\title{
The role of corynebacterial phospholipase D vaccine in activation of macrophages
}

\author{
A.K. Ibrahim ${ }^{1^{*}}$, F.R. El-Seedy ${ }^{2}$, W.H. Hassan ${ }^{2}$ \\ ${ }^{1}$ Biotechnology Center for Services and Researches, Faculty of Veterinary Medicine, Cairo University, Giza \\ 12211, Egypt. \\ ${ }^{2}$ Department of Microbiology, Faculty of Veterinary Medicine, Beni-Suef University, Beni-Suef 62511, Egypt.
}

\begin{abstract}
The role of phospholipase D toxoid (PLD) vaccine in enhancing killing activity of macrophages was demonstrated in this study. Four groups of Balb/c mice were vaccinated with different forms of current vaccines against Corynebacterium pseudotuberculosis ( $C$. pseudotuberculosis). The first group was vaccinated with purified recombinant mutated PLD protein adjuvated vaccine; the second with formalin inactivated whole cells of $C$. pseudotuberculosis adjuvated vaccine, the third group with combined bacterin-toxoid adjuvated vaccine and the fourth was given viable $C$. pseudotuberculosis cells. Mononuclear peritoneal cells from each vaccinated groups were collected and inoculated intraperitoneally into naïve recipient $\mathrm{Balb} / \mathrm{c}$ mice that were subsequently challenged by equal number of live $C$. pseudotuberculosis cells. Killing activity of peritoneal macrophages collected from each recipient group of mice was assayed by cultivation of lysed macrophages on plates of count brain heart agar. It was reported that the highest killing activity of macrophages were those collected from mice vaccinated with recombinant $P L D$ adjuvated vaccine that reaches $95 \%$ of phagocytosed $C$. pseudotuberculosis living bacteria; where those given viable $C$. pseudotuberculosis bacteria $(80 \%)$; then combined vaccine $(69.5 \%)$ and the least killing activity was performed by macrophages obtained from bacterin vaccinated animals.
\end{abstract}

Corynebacterium pseudotuberculosis is a facultative intracellular pathogen that causes caseous lymphadenitis (CLA) in both sheep and goats (Prescott et al., 2002) and oedematous skin disease (OSD) in buffaloes (Selim, 2001). CLA vaccines are currently produced from formalin inactivated phospholipase $\mathrm{D}$ (PLD)-rich $C$. pseudotuberculosis culture supernatants in which PLD is considered the major protective antigen (Eggleton et al., 1991, 2005; Hodgson et al., 1999) or from purified recombinant PLD protein inactivated with detergents (Fontaine et al., 2006).

Nevertheless the immune mechanisms that involved in protection against C. pseudotuberculosis provided by these toxoid vaccines have not yet been clarified. However, the role of humoral immune response resulting in production of antiPLD antibodies is well established. Neutralization of PLD; the major virulence factor of $C$. pseudotuberculosis enhances bacterial dissemination out of the site of infection in host tissues by

\footnotetext{
* Corresponding author. Tel.: +2 0101590672 ;

fax: +2025725240

E-mail address: adel2005khalil@yahoo.com (A. K. Ibrahim)
}

increasing vascular permeability, decreasing chemotaxis of neutrophils and inhibiting the opsonic effect of complement through activation of complement cascade by alternative pathway far out from the invasive pathogen (Batey, 1986; Yozwiak and Songer, 1993).

Adequate protection against CLA is afforded by both humoral and cellular immune responses against such intracellular microorganisms (Jolly, 1965; Cameron and Engelbercht, 1971; Hard, 1975; Irwin and Knight, 1975; Cameron, 1982; Lan et al., 1999; Fontaine et al., 2006).

Early studies reported the importance of cellular immune response represented by development of activated macrophages that eliminate invasive C. pseudotuberculosis from host tissues (Hard, 1969 and Tashjian, 1983). Activated macrophages could be detected in animals infected naturally with CLA or after inoculation of living corynebacteria in experimental animals (Lan et al., 1999; Hard, 1969). On the other hand, inactivated C. pseudotuberculosis antigen could not stimulate activation of macrophages in immunized animals. Lan et al. (1999) reported that activator antigens to 
macrophages are involved in culture supernatants and not cell associated antigens. They reported that these secretory antigens in culture supernatants could stimulate $\mathrm{Th}-1$ subset of $\mathrm{CD} 4^{+}$ $\mathrm{T}$ cells to produce IFN- $\beta$ and TNF- $\alpha$ cytokines; the major activators of macrophages. Factors involved in culture supernatants that could evoke cellular immune response are not previously detected, and the first report about the antigen involved in culture supernatants that can stimulate cell mediated response by $C$. pseudotuberculosis was performed (Walker et al., 1994). They identified $40 \mathrm{kDa}$ protein in culture supernatants and investigated its humoral and cellular immune response activities. PLD although considered as the major virulence of $C$. pseudotuberculosis and its role in establishment of humoral immune response is well identified, yet its role in activation of cellular immunity is not elucidated.

Therefore, the present study was undertaken to examine the role of PLD toxoid vaccine in stimulation of cellular immunity and its correlation in production of activated macrophages.

\section{Materials and Methods}

Bacterial strain. A locally isolated and completely identified strain of C. pseudotuberculosis from clinically infected sheep was kindly provided culture collection at the Biotechnology Center for Services and Research, (BCSR), Faculty of Veterinary Medicine, Cairo University. The isolate is completely identified strain according to standard diagnostic techniques.

Animals. Thirty two 6-weeks-old female Balb/c mice used in the study. Mice were divided into 8 groups; 4 groups, (5 animals/group) that intended for immunization procedures and the other 4 groups ( 3 animal/group) for macrophage transfer. Vaccines.

1. Recombinant PLD inactivated vaccine. The PLD toxoid vaccine was prepared by recombinant DNA technology and used for preparation of genetically engineered vaccine against caseous lymphadenitis (CLA) in sheep (Selim, 2000).

2. Bacterin. It is prepared according to Borgden et al. (1984). Corynebacterium pseudotuberculosis local strain was grown on $0.1 \%$ Tween 80 brain heart broth and incubated for $48 \mathrm{~h}$. at $37^{\circ} \mathrm{C}$ in shaking incubator. Bacterial cells were collected by centrifugation of culture at $4000 \mathrm{rpm}$ for 15 min. in cooling centrifuge. The pellet was washed twice with distilled water, and then washed once with $50 \%$ acetone, once in $100 \%$ acetone, twice with ethyl ether and then air dried. The dried pellet was weighed and suspended in $1 \%$ formalin solution so that each $\mathrm{ml}$ of suspension contained $10 \mathrm{mg}$ of bacterial cells. The formalin suspension was stored in refrigerator for $48 \mathrm{~h}$. Inactivation of bacterial cell was checked by culturing on brain heart agar plates for sterility.

3. Combined recombinant PLD inactivated protein plus bacterin. It is composed of toxoid (recombinant genetically inactivated PLD) combined with bacterin (formalin inactivated Corynebacteria). Provided by Prof. S. A. Selim, (BCSR). The components were suspended in oil adjuvant with a concentration of $50 \mu \mathrm{g}$ recombinant PLD and $10 \mathrm{mg} / \mathrm{ml}$ vaccine.

4. Viable bacteria. By inoculation of group of mice with viable $C$. pseudotuberculosis, a strain isolated from local sheep breeds diseased with CLA.

Immunization of animals. The first group of Balb/c mice was immunized by $0.2 \mathrm{ml}$ of toxoid subcutaneously and then immunization was repeated once after 4 weeks. The second group was immunized with bacterin in a dose of $0.2 \mathrm{ml}$. and then given booster after 4 weeks. The third group was immunized with combined vaccine $(0.2$ $\mathrm{ml}$ subcutaneously) and animals were inoculated with booster dose after 4 weeks. The fourth group of animals inoculated once S/C with $0.2 \mathrm{ml}$ live Corynebacteria $\left(10^{6} \mathrm{CFU} / \mathrm{ml}\right)$.

Macrophage transfer. Peritoneal macrophages were collected from all groups of vaccinated mice as well as from the unvaccinated control ones. Cells were collected essentially as described by (Cameron and Engelbercht, 1971). The mice were killed with chloroform, the abdominal skin was reflected and $3 \mathrm{ml}$ of tissue culture medium RPMI1640 containing 10 units of heparin $/ \mathrm{ml}$ were injected intraperitoneally. The macrophage suspensions from each immunized group were pooled in propylene tubes that were kept in ice to inhibit the adsorption of cells on the walls of the propylene tubes. Macrophages were sedimented by centrifugation at $3000 \mathrm{rpm}$ for 5-10 min., the supernatant was discarded and the collected cell pellets were washed with sterile saline, and then resuspended in non-heparinized RPMI medium using a volume of $0.5 \mathrm{ml}$ for resuspending each pool. The number of collected macrophages was detected by counting the total leukocytic count 
Table (1): Killing assay of macrophages collected from Balb/c mice vaccinated with different types of vaccines.

\begin{tabular}{|c|c|c|c|c|c|}
\hline \multirow{2}{*}{ Inoculum type } & \multicolumn{2}{|c|}{$\begin{array}{l}\text { Mean No. of lysed macrophages } \\
\text { from }\end{array}$} & \multicolumn{2}{|c|}{ Mean No. of CFU/100 $\mu \mathrm{l}$} & \multirow[t]{2}{*}{$\begin{array}{l}\text { Percent of } \\
\text { killing }\end{array}$} \\
\hline & $\begin{array}{c}\text { Recipient } \\
\text { mice }\end{array}$ & $\begin{array}{c}\text { Control } \\
\text { mice }\end{array}$ & $\begin{array}{c}\text { Recipient } \\
\text { mice }\end{array}$ & $\begin{array}{c}\text { Control } \\
\text { mice }\end{array}$ & \\
\hline Toxoid & 116.000 & 116.000 & 3 & 58 & 94.8 \\
\hline Bacterin & 972.000 & 972.000 & 46 & 55 & 16.3 \\
\hline Combined & 116.000 & 116.000 & 7 & 23 & 69.3 \\
\hline Live C.pseudotuberculosis & 972.000 & 972.000 & 11 & 55 & 80.0 \\
\hline
\end{tabular}

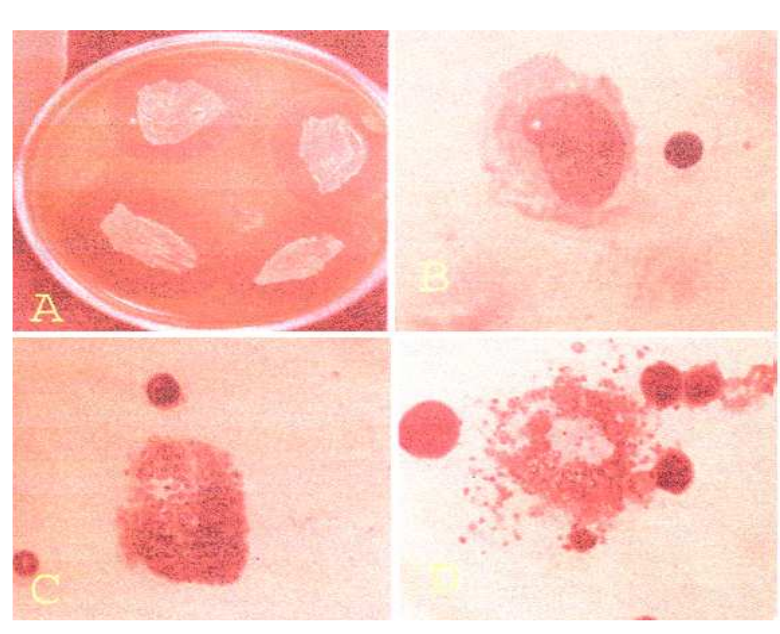

Photo 1: (A) Four strain of C. pseudotuberculosis producing PLD showing synergistic haemolysis with Rhodocoocus equi filtrate. (B) Naïve macrophage showing minimal phagocytic activity. (C \& D) Macrophages collected from mice vaccinated with PLD showing maximal chemotaxis and phagocytosis. using haemocytometer, then counting the percent of monocytes with Giemsa stain smears prepared from the collected peritoneal fluid. The $0.5 \mathrm{ml}$ of pooled macrophages was adjusted to contain macrophages in a concentration of $6 \times 10^{6} \mathrm{cell} / \mathrm{ml}$.

Each pool of macrophages was inoculated intraperitoneally into recipient mouse with a dose of $0.5 \mathrm{ml}$ containing $3 \times 10^{6}$ cells. All recipient mice were challenged 18 hours later by $\mathrm{I} / \mathrm{P}$ infection of $0.5 \mathrm{ml}$ suspension of living $C$. pseudotuberculosis containing $2 \times 10^{6} \mathrm{ml}$ CFU. Control mice ( 3 mice) were also challenged by the same dose of $C$. pseudotuberculosis.

Counting of live bacteria in the peritoneal macrophages. One hour after I/P inoculation of live C. pseudotuberculosis, peritoneal macrophages were collected as previously described but $2 \mathrm{ml}$ saline were used for $\mathrm{I} / \mathrm{P}$ inoculation and after abdominal gentle massage the peritoneal wash was aspirated and dispensed in ice cooled polypropylene tubes. Ten fold serial dilutions were made using sterile distilled water in the first tubes for lysis of macrophages; the subsequent dilutions were made in sterile saline. Tubes with distilled water were incubated at $37^{\circ} \mathrm{C}$ for $15 \mathrm{~min}$. with shaking each $5 \mathrm{~min}$. before making the serial dilutions. Duplicate plate count for each dilution were performed by spreading $0.1 \mathrm{ml}$ of the $10^{-2}$ and $10^{-3}$ dilution on brain heart infusion agar plates. The colonies were counted after incubation at $37^{\circ} \mathrm{C}$ for $48 \mathrm{~h}$.

\section{Results}

The killing assay of macrophages collected from mice vaccinated with toxoid, bacterin, combined (toxoid-bacterin) and living C. pseudotuberculosis are illustrated in (Table 1). The highest killing activity was performed by peritoneal macrophages collected from Balb/c mice with adjuvated recombinant PLD vaccine if compared with the same number of macrophages collected from naïve non vaccinated control $\mathrm{Balb} / \mathrm{c}$ mice (Photo 1). The collected macrophages from recipient mice $(116,000$ cell $)$ challenged by inoculation of live C. pseudotuberculosis and after cultivation of their lysate on brain heart agar media revealed $3 \mathrm{CFU} / 100 \mu \mathrm{l}$ of lysate from recipient mice inoculated $\mathrm{I} / \mathrm{P}$ with macrophages collected from non vaccinated mice as control. The percent of killing of C. pseudotuberculosis was $94.8 \%$ (Photo $1 \mathrm{C}$, D). The least killing activity was performed by macrophages collected from mice vaccinated with formalin inactivated whole cell $C$. pseudotuberculosis. The lysate of macrophages revealed $46 \mathrm{CFU} / 100 \mu \mathrm{l}$ in comparison with $55 \mathrm{CFU} / 100 \mu \mathrm{l}$ of lysed macrophages collected from control mice with a percent of killing activity reached $16.3 \%$. By 
addition of PLD toxoid to the bacterin vaccine and using them for vaccination of third group of Balb/c mice, the percent of killing of $C$. pseudotuberculosis raised to reach $69.5 \%$. Upon vaccination of a fourth group of $\mathrm{Balb} / \mathrm{c}$ mice with a suitable dose of living C. pseudotuberculosis the number of colonies grew from macrophages lysates collected from recipient mice reached 11 $\mathrm{CFU} / 100 \mu \mathrm{l}$ lysate in comparison to $55 \mathrm{CFU} / 100$ $\mu \mathrm{l}$ of macrophage collected from control mice. The killing percent was $80 \%$.

\section{Discussion}

To develop efficient vaccine against any pathogen the protective antigens and virulence factors must be recognized to know the immune mechanism responsible for protection against infection. The immune response against $C$. pseudotuberculosis is complex and includes both humoral and cellular mechanisms (Lolly, 1965; Cameron and Engelbercht, 1971; Hard, 1969, 1970; Cameron, 1972). PLD is now recognized as the major virulence factor involved in $C$. pseudotuberculosis infections and vaccines prepared by formalin inactivation of culture supernatants rich-in PLD or from purified recombinant PLD exotoxin inactivated with detergents offered significant protection against CLA (Eggleton et al., 1991,2005; Burrel, 1983; Fontaine et al., 2006). The role of PLD toxoid vaccines in evoking humoral immune response and production of anti-PLD antibodies is adequately documented (Hodgson et al., 1994). Nevertheless, the role of toxoid PLD vaccine in stimulation of cellular immunity and activation of macrophages is not previously studied. To elucidate this relation between PLD and macrophage activation, a group of $\mathrm{Balb} / \mathrm{c}$ mice was vaccinated with purified recombinant PLD antigen inactivated with site directed mutagenesis to avoid any possible drastic effect of formalin on the antigenicity of the PLD antigen. Peritoneal macrophages collected from immunized mice were assayed for their activation by measuring their killing activity to living C. pseudotuberculosis bacteria. Results in (Table 1) demonstrated that the average killing activity of macrophages from all vaccinated mice was $95 \%$ of phagocytosed cells, which establish a finding that PLD toxoid vaccine could activate phagocytic and killing activity of macrophages. To confirm this finding another group of mice was vaccinated with formalin killed whole cells of C. pseudotuberculosis (bacterin). Collected peritoneal macrophages showed no increase in killing activity (18\%) that equal the same percentage of killing activity provided by peritoneal macrophages collected from control non vaccinated group of mice. This is in agreement with previous studies reporting that inactivated whole cell vaccines could not stimulate killing activity of macrophages (Cameron and Engelbercht, 1971). Some investigators recommended the formulation of CLA vaccines from toxoid and bacterin as a combined vaccine in believe to improve vaccinal efficacy of each component of administrated in single form (Pointkowski and Shivers, 1998; Fontaine et al., 2006).

To evaluate efficacy of combined vaccine in activation of macrophages a third group of mice were vaccinated with combined vaccine composed of the PLD inactivated antigen and bacterin. Macrophages collected demonstrated a killing activity reached $63 \%$ which indicated that addition of inactivated bacteria to toxoid vaccine decreased killing activity of macrophages from $95 \%$ to $63 \%$. These results coincide with investigation of Eggleton et al. (1991) who reported that addition of bacterins did not improve protective efficacy of toxoid vaccines. At the same time did not justify the findings of Pointkowski and Shivers, 1998 and Fontaine et al. (2006) in improving immunological efficacy of toxoid vaccine by addition of bacterins.

To prove that activated macrophages are produced as a result of secretory antigens that include PLD, a group of mice was immunized with live C. pseudotuberculosis. Macrophages collected from these animals showed a high percent of killing activity that reached $80 \%$, that confirmed the investigation of Lan et al. (1999) who attributed activation of cellular immunity to secretory antigens, but not cell associated antigens. These results also agree with data of earlier investigators that reported the activation of macrophages collected from infected animals (Jolly, 1965; Hard, 1969).

The mechanism by which PLD toxoid vaccine could stimulate cellular immunity resulted in production of activated macrophages still needs elucidation, but depending upon the data of the present study and immunologically, it can be proposed that macrophages in case of animals vaccinated with PLD toxoid vaccines were activated due to stimulation of Th-1 subset of 
$\mathrm{CD}^{+} \mathrm{T}$ cells which produced cytokines including IFN- $\beta$ and TNF- $\alpha$, the patent activators of macrophages (Lan et al., 1999) The induction of an adequate Th-1 type T-cell response resulted in production of IFN- $\beta$ may be an essential component in the induction of cellular resistance to C. pseudotuberculosis infection (Tashjian and Campbell, 1983; Simmons et al., 1998). The mechanism by which PLD exotoxin activate Th1 lymphocytes is not elucidated and it can be hypothesized that PLD as exotoxin can interact with immune system cells as superantigen. Superantigens are proteins come from microbial sources such as bacteria and viruses. Several bacterial toxins are currently viewed as superantigens.

The staphylococcus exotoxins are the most known, but the pyogenic exotoxin of Streptococci and a protein with mitogenic properties of Mycoplasma arthridis are also considered as members of that group (Von Regenmortel et al., 1997). Superantigens bind both a specific T-cell receptor VB domain and MHC-II molecules on the antigen presenting cells (APC). They lightly cross link the T-cell and APC resulting in a very powerful T-cell responses which reach $20 \%$ of the animal T-cell. This stimulation is associated with the secretion of unusually large amounts of cytokines as IFN- $\beta$ (Tizard, 2000).

Results of the present investigation provide a conclusion that PLD toxoid vaccines can stimulate both humoral and cellular immune responses which are essential for adequate protection against C. pseudotuberculosis infection and it is therefore not surprising that CLA vaccines formulations that focused upon using PLD as the primary protective antigen have been successful (Burrel, 1983; Eggleton et al., 1991, 2005; Hodgson et al., 1999). On the other hand, the failure of vaccines prepared from inactivated whole C. pseudotuberculosis bacterial cells can be explained by lack of development of anti-PLD antibodies that can abolish the toxic effect of PLD secreted by the invasive microorganism and the inability of bacterin in stimulation of cellular immune response and production of activated macrophages the patent cellular factor in elimination of Corynebacteria.

\section{Acknowledgments}

The authors acknowledge Prof. S. A.Selim for his valuable scientific advises and his critical revision of the manuscript. The study was financed by Egyptian Academy for Scientific Research \& Technology, Grant No. 19.

\section{References}

Batey, R. G. (1986): Pathogenesis of caseous lymphadenitis in sheep and goats. Aust. Vet. J., 63: 269-272.

Brogden, K. A.; Cutlip, R. C. and Lehmkuhl, H. D. (1984): Comparison of protection induced in lambs by Corynebacterium pseudotuberculosis whole cell and cell wall vaccines. Am. J. Vet. Res., 45: 2393-2395.

Burrel, D. H. (1983): Caseous lymphadenitis vaccine. NSW Vet. Pro., 19:53-57.

Cameron, C. M. (1972): Immunity to C. pseudotuberculosis. J. of the South African. Vet. Med. Assoc., 43: 343-349.

Cameron, C. M. (1982): The immunogenicity of Corynebacterium pseudotuberculosis. Proc. Ann. Meat Goat Prod. Dis., 3:458-468.

Cameron, C. M. and Engelbercht, M.M. (1971): Mechanisms of immunity to C. pseudotuberculosis in mice using inactivated vaccine. Onderstepoort. J. Vet. Res., 38: 7382.

Eggleton, D. G.; Doidge, C. V.; Middleton, H. D. and Minty, D. W. (1991): Immunization against ovine caseous lymphadenitis. Efficacy of monocompetent Corynebacterium tuberculosis toxoid vaccine and combined clostridialcorynebacterial vaccines. Aust. Vet. J., 68-320.

Eggleton, D. G.; Haynes, J. A., Middleton, H. D. and Cox, J. C. (2005): Immunization against ovine caseous lymphadenitis: Correlation between Corynebacterium pseudotuberculosis toxoid content and protective efficacy in combined clostridial-corynebacterial vaccines. Aust. Vet. J., 68:322-325.

Fontaine, M. C.; Baird, G.; Connor, K. M.; Rudge, K.; Sales, J. and Donachie, W. (2006): Vaccination confers significant protection of sheep against infection with a virulent United Kingdom strain of Corynebacterium pseudotuberculosis. Vaccine, 24:5986-5996.

Hard, G. C. (1969): Immunity to experimental infection with C. ovis in the mouse peritoneal cavity. Res. Vet. Sci., 10: 547554.

Hard, G. C. (1975): Comparative toxic effect of surface lipid of Corynebacterium ovis on peritoneal macrophages. Infect. Immun., 12: 1439-1449.

Hodgson, A. L.; Carter, K.; Tachedajian. M.; Krywult. J.; Corner, L. A.; MeColl, M. and Cameron, A. (1999): Efficacy of an ovine caseous lymphadenitis vaccine formulated using a genetically inactive form of the Corynebacterium pseudotuberculosis phospholipas D. Vaccine, 17:802-808.

Hodgson, A. L.; Tachedjian, M.; Carner, L. A. and Radford, A. J. (1994): Protection of sheep against caseous lymphadenitis by use of a single oral dose of live recombinant Corynebacterium pseudotuberculosis. Infect. Immun., 62: $5275-5280$.

Irwin, M. R. and Knight, H. D. (1975): Enhanced resistance to Corynebacterium pseudotuberculosis infections associated with reduced serum immunoglobulin levels in levamisoletreated mice. Infect. Immun., 12: 1098-1103. 
Jolly, R. D. (1965): The pathogenic action of the exotoxin of Corynebacterium ovis. J. Comp. Pathol., 75:417-431.

Lan, D. T.; Makino, S. I.; Shirahata, T.; Yamada, M. and Nakane, A. (1999): Tumor necrosis factor alpha and gamma interferon are required for the development of protective immunity to secondary Corynebacterium pseudotuberculosis infection in mice. J. Vet. Med. Sci., 61: 1203-1208.

Pointkowski, M. D. and Shivers, D. W. (1998): Evaluation of commercially available vaccine against Corynebacterium pseudotuberculosis for use in sheep. JAVMA., 212:17651768.

Prescott, J. F.; Menzies, P. I. and Hwang, Y. T. (2002): An interferon-gamma assay for diagnosis for Corynebacterium pseudotuberculosis infection in adult sheep from a research flock. Vet. Microbiol., 88(3): 287- 297.

Selim, S. A. (2000): Establishment of a vaccine for controlling Corynebacterium pseudotuberculosis infection in sheep and buffaloes using recombinant DNA technology. Report of project No (19) sponsored by Egypt. Acdem Sci Res and Technol No (6). 2000.

Selim, S.A. (2001): Oedmatous Skin Disease of Buffalo in Egypt. A Review. J. Vet. Med., 1348:241-258.

Simmons, C. P.; Dunstan, S. J.; Tachdjian, M.; Krywult, J.; Hodgson, A. L. and Strugrell, R. A. (1998): Vaccine potential of attenuated mutants of Corynebacterium pseudotuberculosis in sheep. Infect. Immun., 66: 474- 479.

Tashjian, J. J. and Campbell, S. G. (1983): Interaction between caprine macrophages and an Corynebacterium pseudotuberculosis; an electron microscopic study. Am. J. Vet. Res., 557-561.

Tizard, I. R. (2000): Superantigens. In Veterinary Immunology: An Introduction. $6^{\text {th }}$ ed. Philadelphia: WB Saunders Co.; 106.

Von Regenmortel, M.,;Tellamm, R. L.; Manteca, C.; Mainil, J. and Pastoret, P.P. (1997): Antigens. In Veterinary Vaccinology. (Ed.) Pastaret PP, Blanco J, Vannierand P, Verchurem C.; Elsevier Science B.V. Amestradam, The Netherlands.

Walker, J.; Jackson, H. J.; Wilson, M. J.; Eggleton, D. G.; Meeusen, E. N. T. and Brandon, M. R. (1994): Identification of a novel antigen from Corynebacterium pseudotuberculosis that protects sheep against caseous lymphadenitis. Infec. Immunol., 62:2562- 2567.

Yozwiak, M. L. and Songer, I. G. (1993): Effect of Corynebacterium pseudotuberculosis phospholipase D on viability and chemotactic responses of ovine neutrophils. Am. J. Vet. Res., 53:417-431.

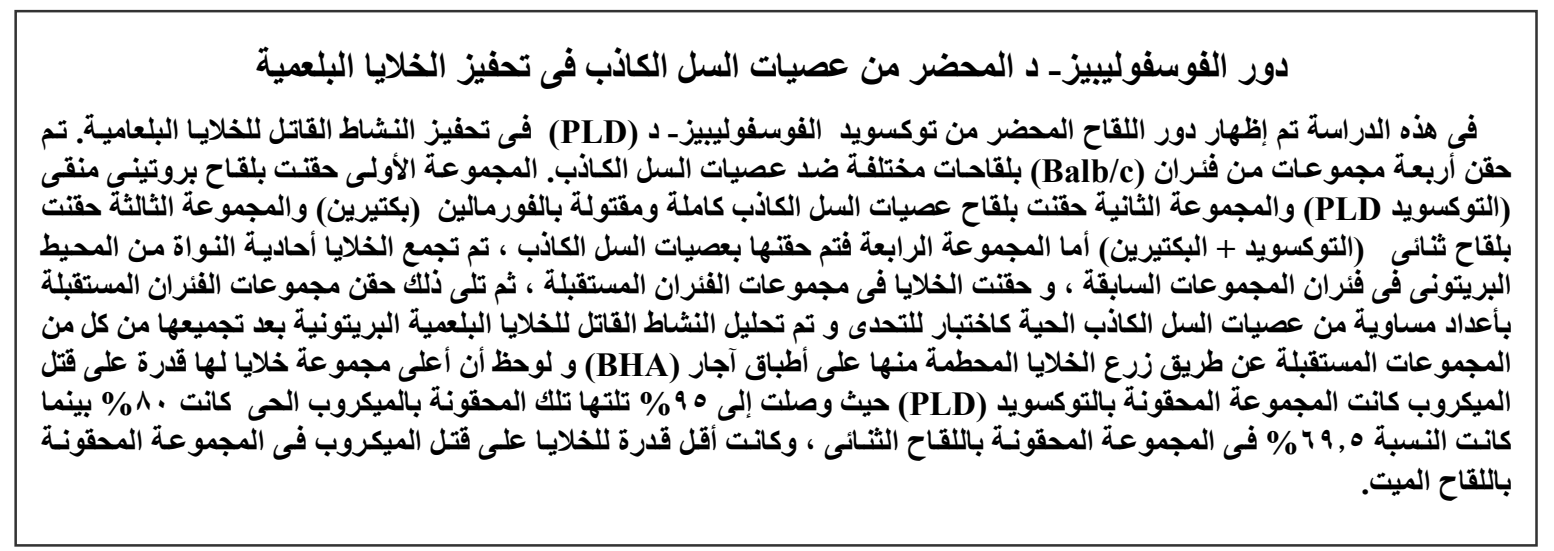

